J. Amer. Soc. Hort. Sci. 120(2)343-346. 1995.

\title{
Distribution of Anacardic Acids Associated with Small Pest Resistance among Cultivars of Pelargonium $\times$ hortorum
}

\author{
Richard Grazzini ${ }^{1}$ \\ Intercollege Graduate Degree Program in Genetics, The Pennsylvania State University, University Park,PA 16802 \\ David Hesk ${ }^{2}$ \\ Schering-Plough, 2015 Galloping Hill Road, Kenilworth, NJ 07233 \\ Ellen Yerger ${ }^{3}$ \\ Department of Entomology, The Pennsylvania State University, University Park, PA 16802
}

Diana Cox-Foster ${ }^{4}$

Department of Entomology, The Pennsylvania State Unversity, University Park, PA 16802

June Medford ${ }^{5}$

Department of Biology, The Pennsylvania State University, University Park, PA 16802

Richard Craig ${ }^{6}$

Department of Horticulture, The Pennsylvania State University, University Park, PA 16802

\author{
Ralph O. Mumma ${ }^{7}$ \\ Department of Entomology, The Pennsylvania State University, University Park, PA 16802
}

Additional index words. phenolic acids, glandular trichomes, geraniums, Geraniaceae, desaturase, omega-5

\begin{abstract}
Composition of anacardic acids (phenolic acids known to be associated with small pest resistance in Pelargonium xhortorum) was examined in 13 diploid and 25 tetraploid cultivars by high-performance liquid chromatography (HPLC). The presence of an unusual desaturation (omega $(\omega)-5)$ in the alkyl tail of anacardic acids present only in glandular trichome exudate of pest-resistant diploid inbred lines had previously been associated with a sticky-trap pest-resistance phenomenon. In this study, we examine Pelargonium cultivars for variability in anacardic acid composition to assess the distribution of $\omega 5$ desaturation among commercial cultivars, to determine possible interactions between $\omega 5$ desaturation and other plant desaturation mechanisms, and to examine the possible impact of ploidy on $\omega 5$ desaturation. An unsaturation index (UI) is derived to compare exudates differing widely in composition yet which may provide a similarly effective sticky-trap pestresistance mechanism based on exudate viscosity. $\omega-5$ Anacardic acids were observed in the glandular trichome exudate of all 38 commercial cultivars examined. No diploid cultivar produced $\omega 5-$ and $\omega 9$ - anacardic acids, although the simultaneous production of $\omega 5$ and $\omega 9$ - anacardic acids was observed in three tetraploid cultivars. Total $\omega 5-$ anacardic acids comprised from 42.4\% (tetraploid cultivar Perlenkette-syn. Snowhite, Weiss) to 86.8\% (tetraploid cultivar Amanda). Commercial $P$. $\times$ domesticum cultivars had no $\omega 5$ anacardic acids. UIs ranged from 60.9 (tetraploid cultivar Dixieland) to 103.4 (diploid cultivar Pinto White). In contrast, anacardic acids collected from a pest-susceptible inbred line contained no $\omega 5-$ anacardic acids and had a UI of 38.7. No significant differences among ploidy levels were observed for UIs or for most specific anacardic acid components, with the exception of $24: 1 \omega 5$ - anacardic acid, in which the mean diploid value (32.1\%) was significantly higher than that of the mean tetraploid value $(27.6 \%)$. We conclude that $\omega 5-$ anacardic acid production occurs in all Pelargonium cultivars observed and that these cultivars are predicted to exhibit resistance to small arthropod pests. Significant genetic variability in specific anacardic acid composition appears to exist among Pelargonium cultivars, suggesting that breeding for pest resistance can be readily monitored by HPLC of anacardic acids.
\end{abstract}

Garden geranium cultivars (Pelargonium $\times$ hortorum) are resistant to many small arthropod pests. A class of simple phenolic acids, anacardic acids (3' alkyl salicylic acid), was discovered to be produced by a diploid $P$. $\times$ hortorum inbred $(71-17-7)$ by

Received for publication. This paper is a portion of thesis submitted by Richard Grazzini in partial fulfillment of the requirement for the $\mathrm{PhD}$ at the Pennsylvania State Univ.' Distinguished professor of environmental quality. The cost of publishing this paper wm defrayed in part by the payment of page charges. Under postal regulations, this paper therefore must be hereby marked advertisement solely to indicate this fact.

'Centre Analytical Laboratories, 304X Research Dr., State College, PA 16801.

${ }^{2}$ Associate principal scientist.

${ }^{3} \mathrm{PhD}$ scholar.

${ }^{4}$ Assistant professor of entomology.

${ }^{5}$ Assistant professor of biology and biotechnology.

${ }^{6}$ Professor of plant breeding, J. Franklin Styer professor of horticultural botany; to whom reprint requests should be addressed,
Gerhold et al. ( 1984) and to be directly responsible for a sticky trap mite-resistance phenomenon investigated by Walters et al. (1989b). Walters (1988) further demonstrated that the anacardic acids from the resistant phenotype were characterized by the presence of an unusual unsaturated [omega (w)-5] alkyl group. The w5 notation indicates that the double bond is located between the fifth and sixth carbon from the methyl end of the alkyl chain. Susceptible phenotypes lack this unusual double bond. Grazzini (1993) determined that the inheritance of the presence of a single double bond in the w5 position was under the control of a single dominant allele. The presence of w5 desaturation also appears to determine the effectiveness of the exudate as a sticky trap (Walters et al., 1989a). Exudate containing large amounts of w5- unsaturated anacardic acids is fluid, adhesive, and effective as a sticky trap; exudate composed mostly of saturated anacardic acids is waxy, nonadhe- 
sive, and without apparent effectiveness as a sticky-trap.

In addition to sticky-trap properties, anacardic acids have also been observed to have direct pesticidal properties via contact toxicity (Gerhold, 1984; Stark, 1975) and via a reduction in fecundity (Grazzini, 1993). Grazzini et al. (1991) demonstrated that crude exudate from a resistant geranium inbred and purified anacardic acids caused in vitro inhibition of prostaglandin endoperoxidc synthase and lipoxygenase, enzymes known or suspected to be involved in insect reproduction (Brady, 1983; StanleySamuelson, 1987; Stanley-Samuelson and Loher, 1986; StanleySamuelson et al., 1986).

Our previous studies have been restricted to inbred lines from a very narrow genetic base. Most of the research compared a single highly resistant inbred (71-17-7) with a single highly susceptible inbred (71-10-1). Walters et al. (1990) determined that these two lines differed in their production of $\omega 5-$ anacardic acids, with exudate from the resistant inbred containing $>80 \% \omega 5-$ anacardic acid, while exudate from the susceptible inbred contained only a small percentage (if any) of $\omega 5-$ anacardic acid. Hesk et al. (1991) refined Walters' anacardic acid analytical system to include mitesusceptible genotypes. They determined that the susceptible inbred (71-10-1) produced anacardic acids with saturated straight alkyl chains, branched alkyl chains, and unsaturated and polyunsaturated alkyl chains in which the double bonds are at positions other than those found in the resistant inbred (71-17-7). Hesk et al. (1991) observed almost no $\omega 5-$ unsaturated anacardic acids in susceptible inbred lines.

Walters et al. (1990) examined the anacardic acid composition of $F_{1}$ hybrids between 71-17-7 and 71-10-1 and determined that the $F_{1}$ had elevated levels of 22-carbon anacardic acids with a corresponding decrease in levels of 24-carbon anacardic acids. Grazzini (1993) suggested that the elevated 22-carbon levels could be explained by either single gene heterosis or complementary dominant epistasis. If the elevated levels of 22-carbon anacardic acids were a general effect of heterosis in Pelargonium, then many $F_{1}$ combinations could be expected to have elevated levels of 22carbon anacardic acids. However, if the occurrence of elevated levels of 22-carbon anacardic acids resulted from an epistatic interaction, then elevated 22-carbon levels among $F_{1}$ hybrids would not be a common occurrence.

The presence of $\omega 5$ unsaturation as an explanation for pest resistance and anecdotal observations of varying degrees of smallpest susceptibility among vegetatively propagated $P$. ×hortorum cultivars suggested a possible relationship between variation in anacardic acid composition and pest susceptibility. In this study, we examined 13 diploid (HOR2) cultivars (including hybrid seedpropagated cultivars) and 25 tetrapioid (HOR4) cultivars (including two seed-propagated cultivars) for possible variation in anacardic acid composition.

\section{Materials and Methods}

Plant material. Tissue specimens from commercial cultivars were sampled from the Penn State Univ. trial gardens (August 1991) and the greenhouses of the Depts. of Horticulture and Entomology (February 1992). The well-characterized pest-resistant (71- 17-7) and pest-susceptible (71-10-1) HOR2 inbreds used in previous studies of Pelargonium trichome biochemistry were sampled during both time periods. Plants were grown under standard field conditions (including weekly overhead watering) or under standard greenhouse conditions. All plants were growing vigorously and of healthy appearance.

Chemical analyses. The analyses for anacardic acid content of the cultivars and the calculation of the unsaturation index (UI) for the anacardic acids were performed as described in Grazzini et al., 1995.

\section{Results and Discussion}

Diploid inbreds, cultivars and $F_{l}$ hybrids. Anacardic acid composition of 13 diploid inbreds, commercial diploid vegetatively propagated cultivars. and commercial seed-propagated $F_{1}$ hybrids are presented in Table 1. All plants examined except for the mite-susceptible 71-10-1 had an exudate comprised predominantly of $\omega 5$ - unsaturated anacardic acid and, therefore, are likely to be resistant to small arthropod pests. There was, however, a

Table 1. Anacardic acid composition of selected diploid Pelargonium $\times$ hortorum cultivars.

\begin{tabular}{|c|c|c|c|c|c|c|c|c|c|}
\hline \multirow{3}{*}{$\begin{array}{l}\text { Diploid (HOR2) } \\
\text { cultivar or inbred line }\end{array}$} & \multirow{3}{*}{$\begin{array}{c}22: 1 \\
\omega 5\end{array}$} & \multicolumn{6}{|c|}{ Percentage of major anacardic acid components ${ }^{2}$} & \multirow{3}{*}{$\begin{array}{l}24: 2 \\
\omega 6,9\end{array}$} & \multirow[b]{3}{*}{ UI } \\
\hline & & $24: 1$ & $\mathrm{C} 23: 1$ & 22:0 & $\mathrm{C} 23: 0$ & 24:0 & 24:1 & & \\
\hline & & $\omega 5$ & $\omega 6$ & & anteiso $^{y}$ & & $\omega 9$ & & \\
\hline Pinto White $\left(\mathrm{F}_{1}\right)$ & 31.7 & 39.7 & 0.0 & 12.6 & 0.0 & 0.0 & 0.0 & 16.0 & 103.4 \\
\hline Red Elite $\left(\mathrm{F}_{1}\right)$ & 25.4 & 37.1 & 3.3 & 6.5 & 6.1 & 7.6 & 0.0 & 14.0 & 93.8 \\
\hline Hot Pink Orbit $\left(F_{1}\right)$ & 36.7 & 28.2 & 2.9 & 10.5 & 4.4 & 4.3 & 0.0 & 12.9 & 93.7 \\
\hline Salmon Orbit $\left(\mathrm{F}_{1}\right)$ & 25.3 & 37.2 & 2.7 & 6.4 & 5.3 & 8.4 & 0.0 & 12.9 & 91.1 \\
\hline Pinto Red $\left(\mathrm{F}_{1}\right)$ & 46.5 & 23.9 & 3.4 & 9.1 & 5.3 & 3.8 & 0.0 & 8.0 & 89.8 \\
\hline Ringo Deep Scarlet $\left(\mathrm{F}_{\mathrm{t}}\right)$ & 49.3 & 29.7 & 4.6 & 6.5 & 5.3 & 2.8 & 0.0 & 0.0 & 83.6 \\
\hline Multibloom White $\left(\mathrm{F}_{1}\right)$ & 14.5 & 35.1 & 0.0 & 23.3 & 3.7 & 7.0 & 0.0 & 13.6 & 76.8 \\
\hline Red Orbit $\left(\mathrm{F}_{1}\right)$ & 25.7 & 25.9 & 3.8 & 11.6 & 8.5 & 16.1 & 0.0 & 4.7 & 64.8 \\
\hline Ben Franklin & 36.0 & 30.9 & 2.3 & 7.2 & 4.3 & 9.0 & 0.0 & 10.3 & 89.8 \\
\hline Snowmass & 33.2 & 28.8 & 4.9 & 7.3 & 4.5 & 12.3 & 0.0 & 7.3 & 81.4 \\
\hline Stadtbem & 54.7 & 24.5 & 0.0 & 8.4 & 6.6 & 5.8 & 0.0 & 0.0 & 79.2 \\
\hline PSU $71-17-7^{\mathrm{x}}$ mite-resistant & 38.9 & 41.7 & 4.8 & 4.9 & 2.0 & 1.4 & 0.0 & 0.3 & 86.0 \\
\hline PSU $71-10-1^{\mathrm{w}}$ mite-susceptible & 0.0 & 0.0 & 0.0 & 26.8 & 7.5 & 25.3 & 7.3 & 15.7 & 38.7 \\
\hline Mean & 35.0 & 32.5 & 2.8 & 9.3 & 4.5 & 6.5 & 0.0 & 8.3 & 86.9 \\
\hline SE & 3.2 & 2.1 & 0.5 & 1.5 & 0.7 & 1.3 & 0.0 & 1.6 & 2.9 \\
\hline
\end{tabular}

Only major components are reported; therefore, values may not sum to $100 \%$.

'The 16-carbon chain possesses a methyl branch at the w3 position.

${ }^{x}$ Standard mite-resistant cultivar used by our laboratory for comparison purposes.

"Standard mite-susceptible cultivar used by our laboratory for comparison purposes. 
substantial amount of variation in composit ion among inbreds and among cultivars. All possessed substantial amounts (4.7\% to $16 \%)$ of $\omega 6,9-$ unsaturated anacardic acids, except for 'Ringo Deep Scarlet' and 'Stadtbern'. The UI is inversely related to the viscosity of the exudate. The mite-susceptible cultivar 71-10-1 possesses a UI of 38.7, giving rise to an amorphous exudate and not providing mite resistance. All other diploid cultivars possessed UIs of much higher values (65 to 103), which we would expect would provide the exudate with the necessary fluidity to act as a sticky trap.

Of the commercial cultivars we observed, 'Pinto White' had the highest unsaturated anacardic acid composition, with a UI of 103.4, whereas 'Red Orbit' had the lowest, with a value of 64.8. These values suggest that the tall glandular trichome exudate of 'Pinto White' would be much more fluid than that of 'Red Orbit' at the same temperature. At relatively low temperatures, the more fluid exudate would remain an effective sticky trap, while at higher temperatures, the more-fluid exudate might become too fluid to be effective. Alternatively, the less-fluidexudate would be more fluid (and, therefore, more effective) at higher temperatures, and less fluid and less effective at lower temperatures. The viscosity, and consequently the sticky-trap property, of the exudate is determined by the number of double bonds and not specifically by the presence of $\omega 5$ double bonds.
In the examinations of Walters et al. ( 1990). in which a pestresistant inbred (71-17-7) and a pest-susueptiblc inbred (71- 10-1) were reciprocally crossed to produce $F_{1}$ hybrids, there were elevated percentages of 22-carbon anacardic acids anti corresponding decreased levels of 24-carbon anacardic acids observed in both $\mathrm{F}_{1}$ hybrid combinations. Grazzini (1993) proposed a two-gene epistasis model for the control of anacardic acid alkyl chain length as one possible explanation for the observed elevated levels of 22carbon anacardic acids in the $F_{1}$ hybrid and supported this hypothesis with observations of appropriate ratios in the $F_{2}$ and backcross generations. In the commercial $F_{1}$ hybrids observed in this report, no such elevation is apparent, at least, not to the extent that it was observed by Walters et al. (1990). The 22-carbon anacardic acid content of the commercial $F_{1}$ hybrids ranged from $31.7 \%$ for 'Salmon Orbit' to $55.8 \%$ for 'Ringo Deep Scarlet'. We conclude that anacardic acid composition is under heritable control, that significant variation for anacardic acid composition exists among commercial cultivars, and that elevated levels of 22-carbon anacardic acids do not significantly occur in all $F_{1}$ hybrids examined in this study.

Hesk et al. (1991) compared the anacardic acid composition of diploid resistant and susceptible inbreds and concluded that in the resistant inbred, there were high level of $\omega 5-$ unsaturated anacardic

Table 2. Anacardic acid composition of selected tetraploid Pelagonium cultivars.

\begin{tabular}{|c|c|c|c|c|c|c|c|c|c|}
\hline \multirow{4}{*}{$\begin{array}{l}\text { Tetraploid } \\
\text { cultivar or inbred line }\end{array}$} & \multicolumn{8}{|c|}{ Percentage of major anacardic acid components ${ }^{2}$} & \multirow{4}{*}{ UI } \\
\hline & $22: 1$ & $24: 1$ & $\mathrm{C} 23: 1$ & 22:0 & $\mathrm{C} 23: 0$ & $24: 0$ & 24: 1 & $24: 2$ & \\
\hline & $\omega 5$ & $\omega 5$ & $\omega 6$ & & anteiso $^{y}$ & & $\omega 9$ & $\omega 6.9$ & \\
\hline & \multicolumn{8}{|c|}{ P. xhortorum (HOK4) } & \\
\hline Veronica & 34.4 & 32.4 & 2.9 & 5.2 & 4.5 & 4.8 & 2.4 & 14.9 & 102.0 \\
\hline Orange Ricard & 38.8 & 28.6 & 2.4 & 11.5 & 4.8 & 3.1 & 0.0 & 10.8 & 91.4 \\
\hline Tetm Scarlet & 33.6 & 29.9 & 2.2 & 11.1 & 4.0 & 4.5 & 0.0 & 12.2 & 90.0 \\
\hline Yours Truly & 32.6 & 27.8 & 2.2 & 6.4 & 5.1 & 8.3 & 2.4 & 12.3 & 89.6 \\
\hline Frau Block & 47.1 & 27.9 & 0.0 & 10.8 & 3.1 & 4.3 & 0.0 & 6.6 & 88.3 \\
\hline Eclipse Red & 40.2 & 31.4 & 2.5 & 9.6 & 4.4 & 3.6 & 0.0 & 6.7 & 87.6 \\
\hline IA-SOS & 41.7 & 30.5 & 2.0 & 10.7 & 4.1 & 4.5 & 0.0 & 6.6 & 87.4 \\
\hline Weis s & 26.6 & 15.8 & 3.0 & 16.9 & 4.0 & 5.8 & 5.6 & 18.2 & 87.4 \\
\hline Americana Rose & 42.9 & 27.6 & 0.0 & 14.5 & 2.3 & 4.4 & 0.0 & 8.4 & 87.2 \\
\hline Amanda & 58.5 & 28.3 & 0.0 & 5.5 & 4.9 & 2.8 & 0.0 & 0.0 & 86.8 \\
\hline Irene & 27.9 & 34.8 & 1.8 & 12.4 & 6.3 & 5.1 & 0.0 & 10.5 & 85.6 \\
\hline Honselers Glorie Lila & 36.2 & 28.3 & 1.7 & 11.6 & 4.9 & 7.9 & 0.0 & 9.4 & 85.1 \\
\hline Centennial & 18.8 & 24.0 & 1.0 & 20.2 & 5.7 & 8.3 & 0.0 & 20.4 & 84.6 \\
\hline Hildegaard & 44.8 & 30.4 & 0.0 & 11.7 & 5.2 & 3.3 & 0.0 & 4.7 & 84.5 \\
\hline Americana Lgt Salmon & 38.2 & 32.1 & 2.7 & 9.0 & 4. 1 & 6.0 & 0.0 & 5.4 & 83.8 \\
\hline Americana Cord & 36.5 & 22.6 & 1.7 & 18.4 & 3.5 & 5.6 & 0.0 & 11.6 & 84.0 \\
\hline PSU 833 & 29.4 & 23.2 & 2.1 & 17.1 & 4.7 & 9.3 & 0.0 & 14.4 & 83.4 \\
\hline IA-330 & 31.4 & 28.8 & 2.4 & 14.7 & 5.5 & 7.7 & 0.0 & 9.5 & 81.5 \\
\hline IA-332 & 51.3 & 24.6 & 2.6 & 9.3 & 6.6 & 4.1 & 0.0 & 0.0 & 78.6 \\
\hline $84-72-6$ & 59.1 & 17.7 & 0.0 & 12.4 & 6.4 & 4.4 & 0.0 & 0.0 & 76.8 \\
\hline Juliette (Risqué) & 26.3 & 21.4 & 2.8 & 13.0 & 7.6 & 15.9 & 0.0 & 13.1 & 76.7 \\
\hline PSU 203 (HGL x Karminball) & 33.3 & 33.4 & 1.8 & 10.5 & 6.5 & 10.5 & 0.0 & 3.4 & 75.3 \\
\hline Paris & 38.3 & 27.2 & 2.0 & 13.2 & 5.5 & 10.3 & 0.0 & 3.5 & 74.5 \\
\hline Freckles & 38.1 & 24.9 & 0.0 & 10.1 & 4.5 & 16.9 & 0.0 & 5.5 & 74.0 \\
\hline PSU 196 (Dixieland) & 31.9 & 29.0 & 0.0 & 12.6 & 7.7 & 18.8 & 0.0 & 0.0 & 60.9 \\
\hline Mean & 38.5 & 27.6 & 1.8 & 11.8 & 5.2 & 7.0 & 0.0 & 7.7 & 83.3 \\
\hline SE & 1.9 & 0.8 & 0.3 & 0.7 & 0.3 & 0.9 & 0.0 & 1.1 & 1.5 \\
\hline$t$ value $(\mathrm{HOR} 4 \neq \mathrm{HOR} 2)$ & 1.00 & 2.64 & 1.70 & 1.74 & 1.10 & 0.33 & NA & 0.31 & 1.3 \\
\hline $\mathrm{df}=34$ & NS & NS & NS & NS & NS & NS & NS & NS & NS \\
\hline
\end{tabular}

'Only major components are reported, therefore values may not sum to $100 \%$.

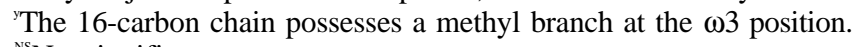

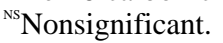


acids and low levels of 24:1 $\omega 9-$ and 24:2 $\omega 6,9-$ anacardic acids Trichome exudate from the susceptible inbred contained virtually no $\omega 5-$ anacardic acids but contained high levels of 24:1 $\omega 9-$ and $24: 2 \omega 6,9-$ anacardic acids. In this examination of commercial cultivars, we observed significant levels of 24:2 $\omega 6,9-$ anacardic acids in diploid cultivars exhibiting high levels of $\omega 5-$ anacardic acids. However, we observed no detectable 24:1 $\omega 9-$ anacardic acids in any of the diploid cultivars observed. We conclude that there are no barriers to the simultaneous production of $\omega 5-$ and $\omega 6,9-$ anacardic acids in the same diploid plant. Indeed, many of the diploid cultivars examined contained $>10 \% \quad 24: 2 \quad \omega 6,9-$ anacardic acid. However, a genetic or competitive biochemical barrier to the simultaneous production of 24:1 $\omega 5-$ and 24:1 $\omega 9-$ unsaturated anacardic acid may exist.

Tetraploid cultivars. In tetraploid cultivars, one might expect that multiplex, simplex, duplex, triplex, and quadriplex allelic states for anacardic acid composition could be isolated. Since almost all tetraploid cultivars are vegetatively propagated, these isolates and their presumably unique anacardic acid composition would be retained through asexual propagation. We examined the anacardic acid profiles of 25 tetraploid cultivars (Table 2) for these allelic effects and observed none. Indeed, the mean values for the individual anacardic acid components were not significantly different between the diploid cultivars and the tetraploid cultivars except for the 24:1 $\omega 5$ - anacardic acid. In this case, on the average, the diploid cultivars contained a significantly higher $(P<0.05)$ amount of the 24:1 $\omega 5$ component. There was a corresponding (but nonsignificant) decrease in the amount of 22:1 $\omega 5$ - anacardic acid. We interpret these observation to indicate that, although a considerable amount of variation exists among cultivars within each ploidy level, there is virtually no difference in anacardic acid composition that can be directly attributed to ploidy level. The range of exudate unsaturation indices varies from a high of 99.7 ('Veronica') to a low of 60.9 ('PSU 196'). This range is very similar to that observed for the diploid cultivars. However, in contrast with the diploid cultivars, some of the tetraploid cultivars contained $\omega 5-, \omega 9-$, and $\omega 6,9-$ unsaturated anacardic acids. The tetraploid cultivar 'Veronica' contained $69.7 \% \omega 5-$ and $\omega 6-$ anacardic acids, 24\% 24:1 $\omega 9-$ anacardic acid, and $14.9 \% \quad 24: 2$ $\omega 6,9-$ anacardic acid.

Transmission of anacardic acids, 05 desaturation, and tall glandular trichomes through interspecific hybridization The tetraploid HOR4 cultivar Veronica had $\omega 5-$ anacardic acids and tall glandular trichomes typical of a pest-resistant HOR2 phenotype (Table 1). The tetraploid PEL4 cultivar Yale (Table 2) had neither tall glandular trichomes nor anacardic acids. However, the primary interspecific hybrid (HXP) between 'Veronica' and 'Yale' and the backcross of the hybrid with 'Veronica' had an abundance of tall glandular trichomes and anacardic acids, including the $\omega 5-$ anacardic acids characteristic of a pest-resistant HOR2 phenotype.

The anacardic acid composition of the HXP interspecific hybrid was very similar to that of the HOR4 parent, although there was a tendency for the HXP to have a slightly elevated 22-carbon anacardic acid content $(50.7 \%$ vs. $39.6 \%$ for 'Veronica'), similar to the increase in 22-carbon content reported by Walters et al. (1991) for $F_{1}$ hybrids between two HOR2 inbred lines.

Trichome exudate from the tetraploid 'Veronica' contained a much higher percentage of 24:1 $\omega 9-$ anti 24:2 $\omega 6,9$ anacardic acids than the diploid resistant inbred (HOR2 71-17-7). The ability to produce these two anacardic acid components was transferred to the primary hybrid with PEL4 'Yale'. However, the percentages produced in the primary $\mathrm{PXH}$ hybrid were about one-half that produced in HOR4 'Veronica' (Table '2).

The synthetic mechanism for $\omega 5$ desaturation appears to be transmitted through interspecific hybridization in a dominant fashion. In an interspecific hybrid between the tetraploid HOR4 cultivar 'Veronica' and the glabrous tetraploid PEL4 cultivar 'Yale', the primary hybrid possessed tall glandular trichomes whose exudate had an anacardic acid composition much like that of a typical resistant HOR2. These observations parallel, at least inferential I $\mathrm{y}$, the presumed hybridization between $P$. inquinans (with tall glandular trichomes) and $P$. zonale (with no tall glandular trichomes) to produce $P$. $\times$ hortorum.

\section{Literature Cited}

Brady, E.U. 1983. Prostaglandins in insects. Insect Biochem. 13:443451.

Gerhold, D. L., R. Craig, and R.O. Mumma. 1984. Analysis of trichome exudate from mite-resistant geraniums. J. Chem. Ecol. 10:713-722.

Grazzini, R.A., D. Hesk, E. Heininger, G. Hildenbrandt, C.C. Reddy. D. Cox-Foster, J. Medford, R. Craig. and R.O. Mumma. 1991. Inhibition of lipoxygenase and prostaglandin endoperoxide synthase by anacardic acids. Biochem. Biophys. Res. Commun. 176(2):775 -780.

Grazzini, R.A. 1993. A biochemical, evolutionary. and genetic model of glandular trichome mediated small pest resistance in Pelargonium xhortorum. PhD diss. The Pennsylvania State Univ., University Park, $\mathrm{Pa}$.

Grazzini, R. A., D. Hesk, E. Yerger, D. Cox-Foster, J.I. Medford, R. Craig, and R.O. Mumma. 1994. Species distribution of biochemical and morphological characters associated with small pest resistance in Pelargonium $\times$ hortorum. J. Amer. Soc. Hort. Sci. 120:336-342.

Hesk, D., L. Collins, R. Craig, and R.O. Mumma. 1991. Arthropodresistant anti -susceptible geraniums: comparison of chemistry, p. 224250. In: P.A. Hedin (ed.). Naturally occurring pest bioregulators. Amer. Chem. Soc. Symp. Ser. No. 449:224-250, Washington, D.C.

Stanley -Samuelson, D.W. 1987. Physiological roles of prostaglandins and other eicosanoids in invertebrates. Biol. Bul. 173:92-109.

Stanley-Samuelson, D.W. and W. Loher. 1986. Prostaglandins in insect reproduction. Ann. Entomol. Soc. Amer. 79:841-853.

Stanley -Samuelson, D. W., J.J. Peloquin, and W. Loher. 1986. Egg-laying in response to prostaglandin injections in the Australian field cricket Teleogryllus commodus. Physiol. Entomol. 11:213-219.

Stark, R.S. 1975. Morphological and biochemical factors relating to spider mite resistance in the geranium. PhD diss. The Pennsylvania State Univ., University Park. Pa.

Walters, D.S. 1988. Biochemical and morphological characteristics involved in the pest resistance mechanisms of geraniums. PhD diss. The Pennsylvania State Univ., University Park, Pa.

Walters, D, S., R. Craig, and R.O. Mumma. 1989a. Glandular trichome exudate is the critical factor in geranium pest resistance to foxglove aphid. Entomol. Expt. Applicata 53: 105-109.

Walters, D. S., H. Grossman, R. Craig, and R.O. Mumma. 1989b. Geranium defensive agents, IV. Chemical and morphological bases of resistance. J. Chem. Ecol. 15:357-372.

Walters, D. S., R. Craig, and R.O. Mumma. 1990. Heritable trichome exudate differences of resistant and susceptible geraniums, p. 317-327, In: J.E. Casida (ed.). Pesticides and alternatives: Innovative chemical and biological approaches to pest control. Elsevier Science Publishers BV, Amsterdam, The Netherlands.

Walters, D.S., J. Harman, R. Craig, and R.O. Mumma. 1991. Effect of temperature on glandular trichome exudate composition and pest resistance in geraniums. Entomol. Expt. Applicata 60:61-69. 